of insect feeding deterants from certain weed and crop plants. Ent. Exp Appl. 24:448-457.

5. M. L. May and S. Ahmad. 1983. Host in the Colorado potato beetle; Searching Mechanisms in relation to oligophagy. In: S. Ahmad, editor, Herbivorous Insects; Host-Seeking Behavior and Mechanisms, pp. 173-199. New York; Academic Press.

6. J. A. Svoboda, J. N. Kaplanis, W. E. Robbins and M.J. Thompson. 1975. Recent developments in insect steroid metabolism. Ann. Rev. Entomol. 20:205-220.

7. F. Matsumara. 1975. Toxicology of In secticides. New York: Plenum Press.

8. E. Kirsten, M. L. Sharma and E. Kun. 1978. Molecular toxicology of $(-)$ erythro-fluorocitrate; selective inhibition of citrate transport in mitochondria and the binding of fluorocitrate to mitochondrial proteins. Molec. Pharmacol. 14:172-184.

Sami Ahmad, Ph.D. is in the Department of Entomology and Economic Zoology, Cook College, Rutgers University.

\title{
A FIRST GLIMPSE AT CHINESE ILSULIN SYNTHESIS
}

$\longrightarrow$ he crown jewel of Chind's biochemical research is its insulin program. Although western scientists are familwith the biotechnological achievements of the insulin program, the names of the scientists leading the project and the manner in which the work was organized were clothed in mystery. The first clue was released in October 1982 when Xinhua, China's Press Agency, announced that Prof. Niu Jingyi of the Institute of Biochemistry, Chinese Academy of Sciences, won one of China's first first-class awards for natural sciences research. In early January 1983, a fascinating document describing the organization of the insulin and the more recent alanine $t R N A$ research projects, entered the public domain in the West.

The successful synthesis of bovine insulin, completed in 1965, so buoyed the Chinese scientific establishment that they attempted a more complex problem, the synthesis of yeast alanine tRNA, beginning in 1968. The tRNA project, successfully completed in 1981, and the synthesis of bovine insulin were only accomplished after overcoming hardships unknown in developed countries, as reported in the paper presented at the Joint U.S.-China Science Policy Conference held in Washington, D.C. in January 1983. According to the scientists and administrators involved in both projects, the problems involved in organizing the studies were considerable. Research expertise and laboratory equipment commonly available in developed countries was nonexistent in China. Enzymes, reagents, and substrates-substances readily purchased in the West-first had to be manufactured before the work could begin, as lack of foreign exchange precluded purchases from foreign countries.

The authors of the paper, among whom are Mr. Hu Yongchang, deputy secretary general and director of the Policy Research Office of the Chinese Academy of Sciences, and $\mathrm{Mr}$. Jiang Chengcheng, deputy head of the Division of Research Programs of the Shanghai Branch of the Chinese Academy of Sciences, afford us a first glimpse into the inner workings of a major scientific project in the People's Republic of China. Although the scientists involved were academicians, the project was organized along the lines of a western corporate research study. Research plans were directed by a "leader group," composed of scientists and administrative personnel that delegated responsibility among the various research institutions involved. Mr. Hu et al. credit the method of organization for the successful outcome of the two studies.

China's scientific community is concentrated at research institutes affiliated with one of three national academies-the Academy of Sciences, the Academy of Medical Sciences, and the Academy of Agricultural Sciences or the universities. The most highly qualified and best trained researchers are with the scientific academies or the major universities including Beijing, Fudan in Shanghai, Nankai in Tianjin, and others. In general, research is confined to one department or institute. One of the reasons for this, according to $\mathrm{Dr}$. Thomas Fingar, Director of Stanford University's U.S.-China Relations Program, is that "bureaucratic problems" in interdisciplinary research are difficult to surmont. Although a Communist country, in-fighting, petty jealousies, and grabs for power have not been eliminated within China's scientific community. These two projects, however, required the facilities and expertise of several research institutions.

The insulin research was carried out through the cooperation of scientists at three separate research facilities: the Shanghai Institute of Biochemistry, the Shanghai Institute of Organic Chemistry, and Beijing Uni- versity's Chemistry Department. The Shanghai Institute of Biochemistry and the Shanghai Institute of Organic Chemistry are known throughout China for the excellence of their scientific work. These two research institutes, the Shanghai Institute of Cell Biology, the Institute of Biophysics, the Biology Department of Beijing University, and the Shanghai No. \& Reagent Factory cooperated in the tRNA synthesis work. These two projects took up so much of the resources of the various research institutes that all other research was disrupted. Dr. Otto Schnepp, Professor of Chemistry at the University of Southern California and former Science $\Lambda$ ttache at the U.S. Embassy in Beijing, was told that approximately 60 individuals were involved in the insulin study at any one time. Thirty scientists from the Shanghai Institute of Organic Chemistry worked on the tRNA project. Dr. Schnepp characterized the insulin project as "a very widespread effort where they mobilized anybody they could." According to Dr. Schnepp, even students at Beijing University "were given work to do in their laboratories." Not even the Cultural Revolution of 1966-76, which interrupted almost all scientific work in China, had a major effect on these studies.

Long-term problems, such as the synthesis of the A and B chains of insulin, were assigned to specific research institutes. Problems considered to be "urgent" were studied by teams of scientists from more than one of the involved institutions. Scientists working on the projects were encouraged to voice their opinions and ideas. When disagreements over proposed procedures arose, as in the early phases of the insulin project when they were unsure whether to pursue chemical or enzymatic synthesis techniques, groups were assigned to carry out each technique, and the most successful methods were adopted.

The Chinese are, quite deservedly, very proud of the results of these two studies. The authors ascribe the success to the high degree of cooperation and exchange among project participants. They were the first to synthesize crystalline bovine insulin, a significant biotechnological achievement. The synthesis of yeast alanine tRNA is considered to be an excellent, albeit somewhat underrated, biochemical accomplishment. The achievements are no less than heroic considering that the projects began without even the most basic facilities.

Myrna Watanabe, Ph.D., is a biologist who has conducted research in China under the auspices of The National Academy of Sciences. 